\title{
Use of IT for effective management of ambulance service in National Health Service
}

\section{Dr. S.M. Dharmaratne}

Postgraduate Institute of Medicine, University of Colombo, Sri Lanka.

\author{
Dr. C.C. James \\ Postgraduate Institute of Medicine, University of Colombo, Sri Lanka.
}

\section{Dr. B. Abeysinghe}

Postgraduate Institute of Medicine, University of Colombo, Sri Lanka.

\section{Dr. R. Hewapathirana}

Postgraduate Institute of Medicine, University of Colombo. Sri Lanka.

Contact e-mail address: buddhika.abeysinghe@gmail.com

eHealth Sri Lanka 2010,1(suppl.1):S21

DOI: http://dx.doi.org/10.4038/sljbmi.v1i0.3565

Only the Abstract is available

\begin{abstract}
Nearly USD four billion is spent annually on the health sector in Sri Lanka. This will utilise 4.2 per cent of GDP (2006). Government health service of Sri Lanka is non-profit oriented and Sri Lanka being a nation which is recovering from economic impacts of the war, it is vital to cost effectively mange heath resources. The ambulances play a crucial role in handling emergencies. However, it is not uncommon to find that the service of an ambulance is not always available when the need arises. Ambulances not being in running condition, non availability of an ambulance driver are some of the shortcomings that can be avoided by proper record keeping. The healthcare system is spending unnecessarily for keeping patients in tertiary institutions waiting to be transferred to their peripheral institutions, This is mainly due to the difficulty faced in knowing where exactly an ambulance currently is. Gathering information about the usage of an ambulance will guide us in the decision making regarding the necessity of an ambulances for a given institution. Servicing the ambulances on time prevents unnecessary repairs and proper routing of ambulances prevents money being unnecessarily spent on fuel, both of which can be easily avoided by the use of IT. Above shortcomings can be avoided by employing a vehicle management system that manages the use of ambulances in a healthcare institution. This system will expedite the current process and will enhance the accountability and cost effectiveness thereby enabling one to obtain the maximum service out of the limited resources available.
\end{abstract}

Keywords - usage of an ambulance, vehicle management system 